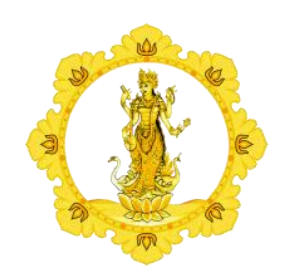

KALANGWAN

JURNAL PENDIDIKAN AGAMA, BAHASA DAN SASTRA

Vol. 9 No. 2 September 2019

\begin{tabular}{|l|l|l|}
\hline p-ISSN : 1979-634X & e-ISSN : 2686-0252 & http://ejournal.ihdn.ac.id/index.php/Kalangwan
\end{tabular}

\title{
UNSUR INTRINSIK DAN PERMASALAHAN SOSIAL DALAM CERPEN ULIAN LACUR KARYA NENGAH RUSMADI
}

\author{
Oleh : \\ I Wayan Nuryana \\ Institut Hindu Dharma Negeri Denpasar \\ E-mail: wayannuryana31@gmail.com
}

Diterima 20 Juli 2019, direvisi 19 Agustus 2019, diterbitkan 2 September 2019

\begin{abstract}
Short story is one of literature in the form of prose. Short story is a work that is built through various intrinsic elements and extrinsic elements. Element element of the short story will build a short story in totality and is artistic. Short stories have intrinsic and extrinsic elements, intrinsic element is the element of the story builder that comes from within the short story itself. If likened to a building, then the intrinsic element is the components of the building. The intrinsic elements are themes, plot, figure, background, point of view and mandate. In addition to intrinsic elements also analyze the social value in this story which contains social problems such as poverty, faded empathy and so forth. As for the benefits of peeling a short story is very diverse, from the first did not know to know, who did not understand to understand, analyze / peel thoroughly a short story is very useful for writers and readers. Writers and readers will very easily understand the contents contained in a short story, especially for people who like to short stories.
\end{abstract}

Keywords: The Ulian Lacur Short Story, Intrinsic Element, Social Issues.

\section{PENDAhuluan}

Pada zaman modern sekarang ini kedudukan sastra semakin meningkat dan semakin penting. Sastra tidak hanya memberikan kenikmatan dan kepuasan batin, tetapi juga sebagai sarana penyampaian pesan moral kepada masyarakat atas realitas sosial.
Karya sastra tercipta dalam kurun waktu tertentu dapat terjadi penggerak tentang keadaan dan situasi yang terjadi pada masa penciptaan karya sastra itu, baik sosial budaya, agama, politik, ekonomi, dan pendidikan, selain itu karya sastra dapat digunakan sebagai dokumen sosial budaya 
yang menangkap realita dari masa tertentu, akan tetapi bukan menjadi keharusan bahwa karya sastra yang tercipta merupakan pencerminan situasi kondisi pada saat karya sastra ditulis.

Sastra adalah hasil karya kreatif yang diciptakan oleh manusia, sebagai subjek penelitian, karya sastra seharusnya tidak dipilah-pilah atau diseleksi yang bersifat teknis, karena setiap karya sastra memiliki kelebihan sekaligus kekurangan masingmasing. Karya-karya sastra terus bermunculan sampai saat ini baik dari karya sastrawan lama maupun sastrawan baru. Ada tiga bentuk karya sastra yaitu puisi, prosa dan drama. Cerpen merupakan salah satu karya sastra berbentuk prosa. Cerpen atau dapat disebut juga dengan cerita pendek merupakan suatu bentuk prosa naratif fiktif. Cerpen cenderung singkat, padat, dan langsung pada tujuannya dibandingkan karya-karya fiksi lain yang lebih panjang, seperti novella dan novel. Cerpen merupakan salah satu jenis karya sastra yang memaparkan kisah atau cerita mengenai manusia beserta seluk beluknya lewat tulisan pendek dan singkat. Selain itu, cerpen atau cerita pendek hanya memberikan sebuah kesan tunggal yang demikian serta memusatkan diri pada salah satu tokoh dan hanya satu situasi saja. Semua yang terdapat dalam cerpen perlu kita gali baik makna maupun pesan yang terdapat di dalamnya.

Manfaat dari mengupas sebuah cerpen sangatlah beragam, dari yang tadinya tidak tahu menjadi tahu, yang tadinya tidak mengerti menjadi mengerti, menganalisis/ mengupas tuntas sebuah cerpen sangat bermanfaat bagi penulis dan pembaca. Penulis dan pembaca akan sangat mudah memahami isi yang terdapat dalam sebuah cerpen khususnya bagi orang yang suka akan cerpen. Dalam ilmu pendidikan khususnya yang mendalami dibidang sastra akan sangat mudah mempelajari dan memahami teori yang digunakan dalam menganalisis sebuah cerpen. Salah satunya yaitu teori sastra strukturalisme.Bila dilihat dari segi unsur intrinsik serta masalah sosial yang terkandung di dalam cerpen Ulian Lacur karya Nengah
Rusmadi sangat menarik untuk dianalisis. Hasil penulisan ini diharapkan dapat memberikan sumbangan perkembangan ilmu sastra, khususnya terkait dengan masalah sosial dalam masyarakat yang dimuat dalam karya sastra cerpen.

\section{PEMBAHASAN}

Cerita pendek (cerpen) telah banyak dibuat dan dikemukakan oleh pakar sastra, dan sastrawan. Jelas tidak mudah membuat definisi mengenai cerpen. Meski demikian, berikut akan dipaparkan Cerita yang panjangnya sepuluh atau dua puluh halaman masih bias disebut cerita pendek tetapi ada juga cerita pendek yang panjangnya hanya satu halaman. Pengertian yang sama dikemukakan oleh Sumardjo dan Saini di dalam buku mereka Apresiasi Kesusastraan. Mereka berpengertian bahwa cerita pendek (atau disingkat cerpen) adalah cerita yang pendek. Tetapi dengan hanya melihat fisiknya yang pendek orang belum dapat menetapkan sebuah cerita yang pendek adalah sebuah cerpen. Adapun cerpen yang akan membahas unsur intrinsik dan permasalahan sosialnya dalam tulisan ini adalah berjudul Ulian Lacur karya Nengah Rusmadi.

\subsection{Unsur Intrinsik Cerpen}

Unsur-unsur pembangun cerpen yang kemudian secara bersama membentuk sebuah totalitas disamping unsur formal bahasa, masih banyak lagi macamnya. Namun secara garis besar berbagai macam unsur tersebut secara tradisional dapat dikelompokkan menjadi dua bagian, yaitu unsur intrinsik dan unsur ekstrinsik. Unsur intrinsik adalah unsurunsur yang membangun karya sastra itu sendiri (Nurgiyantoro, 1994:23). Adapun unsur-unsur intrinsic dari cerpen tersebut sebagai berikut :

\section{a.Sinopsis Cerita}

\section{Ulian Lacur}

Malam gelap ini sebagai saksi, entah kenapa hidupku begitu miskin, sangat jelek nasib yang yang kujalani sebagai manusia.

Saat hari Sabtu Kliwon Wuku Kuningan, saat aku dan Istriku Wayan sedang berada di dapur, lalu terdengar teriakan yang 
memanggil Putu..Putu, Wayan..Wayan.. Ternyata yang memanggil adalah ibunku, lalu memberitahukan bahwa Ayahku sedang mengalami sakit perut. Aku lalu mencari Ayahku dan mengajaknya ke bidan untuk berobat.

Setelah sampai di Bidan lalu Bu Yani memeriksa ayah, ternyata ayah terkena penyakit usus buntu dan harus segera mendapat penanganan. Bu Yani mengatakan bahwa harus segera dibawa ke rumah sakit dan dia akan menemani kesana. Aku pun kebingungan mencari mobil, lalu memutuskan meminta bantuan Pak Gede , meskipun Pak Gede meminjamkan dengan tidak ikhlas.

Sesampainya di rumah sakit lalu ayah diperiksa oleh dokter. Setelah mendapatkan hasil, diberitahukan bahwa ayahku mengalami sakit usus buntu yang sudah parah dan harus segera dioperasi dengan biaya empat juta. Aku pun sangat terkejut dan kebingungan mencari uang sebanyak itu.

Keesokan harinya aku pulang dan meminjam uang di LPD dengan tanah sebagai jaminannya. Lalu kembali ke rumah sakit, namun sebelum ke administrasi aku terlebih dahulu melihat ayah ke kamar. Sesampainya disana aku sudah melihat ibu melamun dan melihat ayah sudah kaku ditutup kain dan sudah tidak bernafas.

b. Insiden

Insiden Menurut Sukada (2007: 2223) "insiden adalah suatu kejadian atau peristiwa yang terdapat dalam cerita, besar kecilnya peristiwa semua itu merupakan kerangka yang membangun struktur sebuah cerita. Insiden-insiden data diuji apakah ada atau tidak hubungannya yang satu dan lainnya. Adapun insiden dari cerpen Ulian Lacur karya I Nengah Rusmadi adalah sebagai berikut :

- Insiden I : insiden yang pertama yaitu ibu dari Putu datang mengabarkan bahwa ayahnya sedang dalam keadaan sakit perut yang sangat keras.
- Insiden II : insiden yang kedua yaitu ayahnya diajak ke bidan, dan diketahui bahwa sakitnya adalah usus buntu dan harus dirujuk ke rumah sakit.

- Insiden III : insiden yang ketiga adalah Putu meminjam mobil namun tidak diberi dengan ihklas oleh Pak Gede.

- Insiden IV : insiden selanjutnya yaitu ayah diajak ke rumah sakit dan diketahui bahwa ayahnya harus segera dioperasi.

- Insiden V : insiden selnjutnya adalah Putu kebingungan mencari biaya lalu memutuskan untuk meminjam ke LPD dengan jaminnan tanah.

- Insiden VI : insiden yang terakhir adalah saat Putu sudah mendapatkan uang lalu dia pergi ke rumah sakit namun ayahnya sudah meninggal.

c. Alur/Plot

Alur menurut Welleck and Warren (1989: 284), “..secara tradisional alur adalah struktur naratif sebuah drama, dongeng, atau novel, unsur naratif alur terbentuk dari adanya unsur-unsur yang lebih kecil yaitu episode-episode yang disebut dengan insiden". Alur ialah rangkaian cerita yang dibentuk oleh tahapan-tahapan peristiwa sehingga menjalin sebuah cerita yang dihadirkan oleh para pelaku dalam suatu cerita. Ada beberapa tahapan-tahapan peristiwa dalam suatu cerita. Tahapantahapan peristiwa tersebut antara lain: pengenalan, pemunculan konflik, klimaks, penyelesaian. Alur dalam cerpen Ulian Lacur ini merupakan alur maju , karena kisah dalam cerpen ini dimulai dengan proses pengenalan, konflik, klimaks dan penyelesaian.

- Tahap Pengenalan 
Pada awal kisah ini pengarang mulai melukiskan suatu keadaan. Kisah ini berawal dari tokoh utama mengenalkan keadaannya dengan menggambarkan keadaannya yang memperihatinkan dimana dia mengalami keadaan miskin (tiwas). Disana juga diceritakan istrinya hanya memasak ikan teri (be gerang) karena tidak bias membeli lauk lainnya. Hal ini dapat kita lihat dari kutipan cerita sebagai berikut :

"Peteng dedet puniki pinaka saksi sebet kenehé tan kadi-kadi. Ulian nasibé jelék tampi tiang dadi manusa ané tumbuh di guminé tiwas nékték. Yén umpamiang rasané uyah lengis nu makékéh mancan ngidang ngurabang anggo darang nasi. Sané mangkin Hyang Widi né micain pica sané ten ngidang rasané tiang manampi. Yén dadi seselang, pang sesai makita mamisuh, maseselan. Tuah ja mula niki sampun jalan idupé sané dados peduman."...... ( paragraph 1 dalam cerpen Ulian Lacur)

- Tahap Pemunculan Konflik

Tahap pemunculan konflik dalam cerpen Ulian Lacur ini dimulai ketika ibu (meme) tokoh utama tergesa-gesa memanggil-manggil tokoh utama yang terkejut dan terheran karena ibunya datang mendadak malam-malam. Disana ibunya menyampaikan kepada Putu (tokoh utama) bahwa ayahnya sedang mengalami sakit perut dan meminta Putu untuk melihat ayahnya. Setelah bertemu dengan ayahnya Putu lalu mengajak ayahnya ke bidan di dekat rumahnya. Hal ini dapat dilihat dalam kutipan dibawah ini :

.... "Putu... Putu... Wayan... Yan...," kénten anaké nika kauk-kauk di subané neked di aep umahé. "Yéh Mémé, kénkén sampun peteng kaukkauk?" tiang matakon éran nepukin abahné mémé buka kéto. "Yan Bapan cainé nyakitang basang uling tunian kanti malisah." Saut ragané kanti angkih-angkih ulian malaib wawu.)"... ( paragraph 2 dalam cerpen Ulian Lacur)

\section{- Tahap Klimaks}

Tahap klimaks dari alur cerpen ini adalah ketika itu setelah ayahnya didiagnosa terkena penyakit usus buntu, $\mathrm{Bu}$ Yani merujuk agar ayahnya dibawa ke rumah sakit karena sakit ayahnya harus segera ditangani. Disana Putu meminta bantuan ke Pak Gede agar mau mengantar ayahnya ke rumah sakit. Sesampainya di rumah sakit dan diketahui ayahnya harus segera dioperasi. Namun karena tidak mempunyai uang ayahnya belum bias dioperasi. Bagian ini dapat dilihat pada pertengahan cerita sebagai berikut :

....."Puniki Pak, bapaké kena pinyungkan usus buntu sané ampun parah, arus dioperasi secepatné niki. Mangkin unduk biaya sané arus sediang Bapak petang juta, nika sampun polih potongan sawiréh Bapak nganggo kartu miskin." Punika raos dokteré nyelasang. "Pak..., Pak ten dados prasi dumun, nanging biayané tiang mutang? Tulungin ja tiang Pak, bapan tiangé ampun ten ngidang naanang." Tiang ngenduk ngidih tulung. "Kanggéang dumun Pak, taler ampura banget yén ten wénten jinah ten dados. "Saut dokteré laut magedi.... ( paragraph 3 dalam cerpen Ulian Lacur)

Disini diceritakan tokoh utama mengalami kebingungan dan tekanan batin yang sangat tinggi karena bingung mencari uang untuk membayar penanganan operasi ayahnya. Sampai akhirnya ia meminjam uang di LPD dengan tanah sebagai jaminannya.

.. "Semengan pesan tiang ampun
numpang bis mulih ka désa.
Sadurungé mulih tiang mabesen kén
mémé mangda becik-becik nongosin
bapa dini.

.. "Semengan pesan tiang ampun numpang bis mulih ka désa. Sadurungé mulih tiang mabesen kén bapa dini. 
Neked di désa, tiang ka LPD nyelang jinah nganggo wala surat tanah. Tiang polih jinah limang juta."... ( paragraph 4 dalam cerpen Ulian Lacur)

- Tahap Penyelesaian

Pada bagian penyelesaian ini menceritakan akhir yang sedih yaitu dimana ayah dari Putu meninggal karena terlambat mendapat penanganan medis. Tokoh utama dan ibunya sangat sedih akan hal itu. Dapat dilihat pada bagian akhir cerita:

.... "Mulih uli LPD, tiang malih ka rumah sakit makta jinah ka pegawai administrasi. Nanging sadurungé mrika tiang nengokin bapa ka kamar. Ring kamar dapetang tiang mémé suba bengong. Angkian tiangé sarasa nyat nyingakin bapan tiang suba makudung kekeh sing maangkian." "Bapa...!!!"... ( paragraph 6 dalam cerpen Ulian Lacur)

Berdasarkan paparan alur tersebut, tampak alur cerita menggunakan alur maju.

\section{d.Tema}

Dick Hartoko dan B.Rahmanto (1986: 67) mengatakan tema merupakan struktur karya sastra yang mempunyai peran penting dalam suatu cerita. Biasanya pengarang merumuskan tema sebelum menulis cerita karya sastra karena gagasan yang sudah dibuat pengarang akan dikembalikan dan cerita yang dibuat tidak keluar dari tema.

Tema yang diangkat dari cerpen ini adalah kemiskinan. Dilihat dari tema yang diangkat, isi cerita ini menggambarkan tokoh utama yang berada pada situasi melarat dan diakhiri dengan kesedihan. Dapat dilihat pada paragraf pertama dalam cerpen tersebut yang menceritakan keadaan tokoh utama, sebagai berikut :

..." Peteng dedet puniki pinaka saksi sebet kenehé tan kadi-kadi. Ulian nasibé jelék tampi tiang dadi manusa ané tumbuh di guminé tiwas nékték. Yén umpamiang rasané uyah lengis nu makékéh mancan ngidang ngurabang anggo darang nasi....

Dalam kutipan cerpen tersebut menggambarkan kemiskinan dari kehidupan tokoh utama dan keluarganya yang dimana mereka hanya makan seadanya.

\section{e. Tokoh dan Penokohan}

Tokoh adalah pelaku yang mengemban peristiwa dalam cerita fiksi sehingga peristiwa itu mampu menjalin suatu cerita (Aminuddin dalam Nurgiyantoro, 1994:79). Menurut Jones (dalam Nurgiyantoro 1994:165) penokohan adalah gambaran yang jelas tentang seseorang yang ditampilkan dalam sebuah cerita. Pengertian ini mengacu pada bagaimana cara pengarang memberikan perwatakan pada tokoh-tokoh ceritanya.

Adapun tokoh utama yang terdapat di cerpen ini adalah : Putu Sida. Tokoh tambahan yaitu Wayan (istri Putu), Wayan Srija (ayah), Ibu, Pak Gede, Bu Yani, Dokter. Dalam cerpen ini Putu Sida merupakan tokoh utama yang menceritakan tentang kisahnya. Adapun penokohan dari masing-masing tokoh sebagai berikut :

\section{- Putu Sida}

Tokoh utama dalam cerita ini memiliki sifat yang bertanggung jawab, penyayang, dan berbakti kepada orang tua. Meskipun disini tokoh utama memiliki keadaan yang kurang mampu, tokoh utama tetap memiliki saya saying dan bertanggung jawab atas orang tuanya, sampai dia rela meminjam uang dengan jaminan tanahnya. Hal ini dapat dilihat pada bagian :

"Semengan pesan tiang ampun numpang bis mulih $\mathrm{ka}$ désa. Sadurungé mulih tiang mabesen kén mémé mangda becik-becik nongosin bapa dini.

Neked di désa, tiang ka LPD nyelang jinah nganggo wala 
surat tanah. Tiang polih jinah limang juta."

- Pak Gede

Tokoh Pak Gede dalam cerpen tersebut adalah seorang yang pelit dan sombong, adapun sifatnya tidak sepantasnya seperti itu karena dia tidak peduli dan tidak merasa simpati dengan keadaan ayah Putu. Pada saat itu Putu ingin meminta bantuan kepada Pak Gede namun justru Pak Gede terlebih dahulu menanyakan Putu punya uang apa tidak dengan raut muka yang tidak ramah. Hal itu dapat dilihat pada kutipan :

"Lédangang Pak Gedé, tiang ba peteng mriki, tiang jagi ngidih tulungan mangkin sareng Pak Gedé. Bapan tiangé sakit sangét mangkin arus ka rumah sakit. Pak Gedé kayun nganter ka rumah sakit?" kénten tiang ngesor ngidih tulungan.

"Ngelah pipis cai kar anggon mayah?" saut ragané malih.

"Pak, mangkin tiang déréng ngelah jinah, nanging benjang tiang kar ngadep sampi. Kanggoang benjang wawu bayah tiang." Tiang masaut seken.

"Nah, ba ya kéto. Men jani dija bapan cainé?" ragané matakon sambilanga nguasang jemak sereg montoré.

- $\mathrm{Bu}$ Yani

Adapun $\mathrm{Bu}$ Yani dalam cerpen ini adalah sebagi bidan yang dimana beliau dimintai tolong memeriksa ayahnya. Bu Yani disini memiliki sifat yang baik hati, hal tersebut dapat dilihat dari dia bersedia memeriksa ayahnya Putu meskipun sudah malam sekali dan juga bersedia ikut mengantarkan ke rumah sakit. Dapat kita lihat pada bagian :

"Pak Putu, niki bapak kena pinyungkan usus buntu, arus aba ka rumah sakit. Mangkin! Mrika ngrereh montor dumun tiang prasida nyarengin. Yén ten kénten tiang jejeh nyanan bapa nyangetang laut tan katulung." Raos bidan seken pesan.

\section{f. Latar/setting}

Menurut Suharianto (1982:22) latar adalah tempat atau waktu terjadinya cerita. Suatu cerita hakikatnya tidak lain adalah lukisan peristiwa atau kejadian yang menimpa atau dilakukan oleh satu atu beberapa orang tokoh pada suatu waktu di suatu tempat. Karena manusia atau tokoh cerita tidak pernah dapat lepas dari ruang dan waktu maka tidak mungkin ada cerita tanpa latar atau setting. Berdasarkan beberapa pendapat tersebut dapat dipahami bahwa latar adalah tempat, waktu, dan suasana terjadinya peristiwa yang dijadikan latar belakang penceritaan oleh pengarang yang keberadaannya harus integral dengan unsur lainnya dalam membangun keutuhan makna cerita. Jadi, latar dalam cerita pendek salah satu unsur yang perlu diperhatikan karena latar akan mendukung kemenarikan sebuah cerita pendek.Adapun latar yang terdapat dalam novel ini yaitu dibagi menjadi empat yaitu latar tempat, waktu, suasana dan sosial.

\section{Latar tempat}

Berikut merupakan latar tempat yang terdapat dalam cerpen tersebut :

- Di rumahnya Putu, ketika itu Putu dan istrinya Wayan sedang memasak dan tibatiba ibunya datang membawa kabar ayahnya.

Usan sangkep, tiang marasa basangé seduk sajan, neked jumah tiang $k a$ paon. Di paon dapetang kurenané sedeng ngoréng gerang. 
- Latar tempat selanjutnya yaitu di rumah orang tuanya, disana Putu melihat ayahnya sedang kesakitan.

Neked delod dapetang bapan tiang sampun lemet tan sida naanang sakit. "Ngidang Bapa majalan?" tiang matakon.

- Di Puskemas, ketika itu ayahnya diperiksa oleh Bu Yani.

Di subané di aep puskesmas tiang ngetok pintu. "Bu... Bu Yani," tiang kauk-kauk sambilang ngetok jelané.

- Di rumah sakit, karena sakit dari ayahnya harus segera ditangani merka dirujuk untuk ke rumah sakit.

Montoré majalan becat, sawatara jam solas neked di rumah sakit umum. Ibu bidan langsung tuun ngalih tongos informasiné. Uli montoré cingak tiang sampun teka perawaté makta tandu sané maroda.

2. Latar Waktu

Latar waktu dalam cerpen ini yaitu Saniscara Kliwon Wuku Kuningan, saat malam hari dan juga pagi hari.

- Latar waktu Saniscara Kliwon Wuku Kuningan yaitu pada bagian awal cerita.

"Lacuré majumu ring petengé nika Saniscara Kliwon Wuku Kuningan,

- Di malam hari ketika itu dimulai ceritanya pada malam hari sampai dengan di rumah sakit.

“..Yéh Mémé, kénkén sampun peteng kauk-kauk?" tiang matakon éran nepukin abahné mémé buka kéto..."

- Latar pagi hari yaitu ketika Putu pulang kerumah dan mencari pinjaman uang ke LPD lalu kembali lagi ke rumah sakit.

“.Semengan pesan tiang ampun numpang bis mulih $k a$ désa. Sadurungé mulih tiang mabesen kén mémé mangda becik-becik nongosin bapa dini. Neked di désa, tiang ka LPD nyelang jinah nganggo wala surat tanah. Tiang polih jinah limang juta. Mulih uli LPD,

\section{Latar Suasana}

Adapun secara keseluruhan suasana dalam cerpen ini adalah menyedihkan dan kepanikan, yaitu dimana pada saat itu ayah Putu mengalami sakit usus buntu dan harus segera ditangani namun dokter tidak mempunyai cukup uang untuk membayar, Putu pun mengalami kepanikan. Dan pada bagian akhir terjadi kesedihan karena ayahnya pada akhirnya meninggal karena terlambat mendapat penanganan.

\section{g. Sudut Pandang}

Titik pengisahan disebut juga sudut pandang pencerita dapat diartikan sebagai siapa pengarang dalam sebuah cerita. Herman. J. Waluyo (2002: 184) menyatakan bahwa point of view adalah sudut pandang dari mana pengarang bercerita, ataukah ia sebagai orang yang terbatas. Point of view juga berarti dengan cara bagaimanakah pengarang berperan, apakah melibatkan langsung dalam cerita sebagai orang pertama, apakah sebagai pengobservasi yang terdiri di luar tokoh-tokoh sebagai orang ketiga. Adapun sudut pandang yang dipergunakan oleh pengarang terhadap cerpen tersebut adalah sudut pandang orang pertama (tiang). Hal ini dapat kita lihat pada keseluruhan cerita mempergunakan kata "tiang" atau aku. Dapat dilihat dalam kutipan berikut :

"Pak, mangkin tiang déréng ngelah jinah, nanging benjang tiang kar ngadep sampi. Kanggoang benjang wawu bayah tiang." Tiang masaut seken.

h. Amanat

Sebuah karya sastra tentulah menyiratkan amanat bagi pembacanya. Definisi amanat menurut Panuti Sudjiman (1988: 57) adalah ajaran moral atau pesan yang ingin disampaikan oleh pengarang. Amanat yang terkandung dalam cerpen ini bersifat implisit atau tersirat. Kita harus memahami maknanya dengan mencermati setiap perilaku dan sikap yang ditunjukan oleh masing-masing tokoh. Adapun makna yang dapat diambil setelah peneliti mencermati 
sikap dan perilaku dalam cerpen tersebut adalah hendaknya kita harus selalu menolong seseorang dengan iklas tanpa memandang imbalan yang kita dapatkan, kita tidak boleh mencontoh Pak Gede dimana dia bersikap pamrih, padahal keadaan dari ayah Putu sangatlah gawat. Selain itu ada hal yang perlu dicermati juga yaitu Putu sebagai tokoh utama disini menyesali kehidupannya yang miskin, hal tersebut memberikan kita pelajaran bahwa sebaiknya kita semangat menempuh karir kita agar tidak bernasib sama seperti Putu yang kehilangan ayahnya karena masalah ekonominya, meskipun disini tidak diceritakan Putu atau tokoh utama menjadi miskin dikarenakan faktor apa.

\subsection{Masalah Sosial dalam cerpen Ulian Lacur}

Permasalahan sosial merupakan sebuah gejala atau fenomena yang muncul dalam realitas kehidupan bermasyarakat. Dalam mengidentifikasi permasalahan sosial yang ada di masyarakat berbeda-beda antara tokoh satu dengan lainnya. Masalah sosial adalah perbedaan antara harapan dan kenyataan atau sebagai kesenjangan antara situasi yang ada dengan situasi yang seharusnya. Dalam segi ekonomi ini biasanya timbul masalah sosial seperti kemiskinan dan pengangguran yang seharusnya menjadi tanggungjawab pemerintah. Hal seperti ini bisa terjadi karena minimnya lapangan pekerjaan yang disediakan oleh pemerintah. Adapun permasalahan sosial yang terjadi dalam cerpen Ulian Lacur sebagai berikut :

\section{a. Kemiskinan}

Yang pertama yaitu kemiskinan, diartikan sebagai suatu keadaan ketika seseorang tidak sanggup memelihara dirinya sendiri sesuai dengan taraf kehidupan dan juga tidak mampu memanfaatkan mental maupun fisiknya dalam mencari penghasilan untuk penghidupan. Adapun dalam cerpen ini adalah menceritakan seseorang yang begitu amat miskin, hal itu digambarkan pada awal cerita. Hal ini adalah salah satu permasalahan yang terjadi dimana Putu sebagai tokoh utama disini menyesal dengan dirinya karena dia miskin dan akibat keadaan tersebut ayahnya tidak bias terselamatkan.

\section{b. Hilangnya rasa empati dan keikhlasan}

Empati adalah proses kejiwaan seseorang individu larut dalam perasaan orang lain baik suka maupun duka, dan seolah-olah merasakan atupun mengalami apa yang dirasakan atu dialami oleh orang tersebut. Empati merupakan kelanjutan dari sikap simpati, yaitu perbuatan nyata untuk mewujudkan rasa simpatinya itu. Dalam cerpen ini terjadi permasalahan sosial dimana hilangnya rasa empati, contohnya tokoh Pak Gede menanyakan Putu punya uang atau tidak saat dimintai bantuan. Hal tersebut mencerminkan bahwa tidak adanya rasa empati kepada sesama dan juga tidak adanya rasa keikhlasan tokoh Pak Gede membantu tokoh utama.

c. Permasalahan dalam pelayanan kesehatan

Dokter dan profesional kesehatan dan petugas-petugas yang menyertai tugas-tugas dokter sering kali terperangkap dalam sistem yang membuat mereka tidak berdaya sebagaimana yang dialami oleh dokter dalam cerpen Ulian lacur. Pihak rumah sakit, sering kali mengalami kasus-kasus yang mirip dengan ilustrasi kasus di atas, beberapa diantaranya di-blow up di media, sehingga membuat citra rumah sakit atau institusi pelayanan itu menjadi buruk dan tidak mengenal unsur kemanusiaan sama sekali. Munculnya kasus-kasus yang mirip-mirip dengan kasus di atas hanyalah akibat dari permasalahan pendanaan kesehatan di Indonesia.

\section{PENUTUP}

\subsection{Kesimpulan}

Cerita pendek (cerpen) telah banyak dibuat dan dikemukakan oleh pakar sastra, dan sastrawan. Jelas tidak mudah membuat definisi mengenai cerpen. Meski demikian, berikut akan dipaparkan Cerita yang 
panjangnya sepuluh atau dua puluh halaman masih biasa disebut cerita pendek tetapi ada juga cerita pendek yang panjangnya hanya satu halaman. Unsur-unsur intrinsik tersebut adalah tema, alur, tokoh, latar, sudut pandang dan amanat. Permasalahan sosial merupakan sebuah gejala atau fenomena yang muncul dalam realitas kehidupan bermasyarakat. Dalam mengidentifikasi permasalahan sosial yang ada di masyarakat berbeda-beda antara tokoh satu dengan lainnya. Masalah sosial adalah perbedaan antara harapan dan kenyataan atau sebagai kesenjangan antara situasi yang ada dengan situasi yang seharusnya. Adapun permasalahan dalam cerpen Ulian Lacur adalah kemiskinan, rasa empati yang hilang, dan pelayanan kesehatan.

\section{DAFTAR PUSTAKA}

Endraswara, Suwardi. 2011. Metodologi Penelitian Sastra. Yogyakarta : CAPS.
Henry, Guntur Tarigan. 2003. Prinsip-Prinsip Dasar Sastra. Bandung: Angkasa.

Ibrahim. 2015 Metodologi penelitian Kualitatif. Bandung : Alfabeta, CV

Nurgiantoro, Burhan. 1994. Teori Pengkajian Fiksi. Yogyakarta: Gajah Mada University Press.

Santana, Septiawan. 2007. Menulis Ilmiah : Metode Penelitian Kualitatif. Jakarta: Yayasan Obor Nusantara.

Susanto, Dwi. 2016. Pengantar Kajian Sastra. Yogyakarta: CAPS.

Wellek, Rene dan Austin Warren. 1989. Teori Kesusastraan.

Jakarta: PT.Gramedia Pustaka Utama 